\title{
Membrane Changes Associated with Platelet Activation
}

\author{
EXPOSURE OF ACTIN ON THE PLATELET SURFACE \\ AFTER THROMBIN-INDUCED SECRETION
}

\author{
James N. George, Roger M. Lyons, and Rebecca K. Morgan, \\ Division of Hematology, Department of Medicine, \\ University of Texas Health Science Center at San Antonio and \\ Veterans Administration Hospital, San Antonio, Texas 78284
}

A B S T RACT The effect of aggregation and secretion on membrane proteins was studied in washed human platelets. Reversible aggregation without secretion was stimulated by ADP and secretion without aggregation was stimulated by thrombin in the presence of EDTA. No loss of platelet surface glycoproteins occurred during reversible ADP-induced platelet aggregation, as measured by quantitative polyacrylamide gel electrophoresis analysis of platelets that were labeled with ${ }^{125}$ I-diazotized diiodosulfanilic acid (DD ${ }^{125}$ ISA) before ADP stimulation. Also, no new proteins became exposed on the platelet surface after ADP aggregation, as determined by $\mathrm{DD}^{125}$ ISA labeling after stimulation. Thrombin-induced platelet secretion also caused no loss of platelet surface glycoproteins. However, after platelet secretion two new proteins were labeled by DD ${ }^{125} \mathrm{ISA}:(a)$ actin and $(b)$ the 149,000 -mol wt glycoprotein (termed GP-G), which is contained in platelet granules and secreted in response to thrombin. The identity of DD ${ }^{125}$ ISA-labeled actin was confirmed by four criteria: $(a)$ comigration with actin in three different sodium dodecyl sulfate-polyacrylamide gel electrophoresis systems, $(b)$ elution from a particulate fraction in low ionic strength buffer, (c) co-migration with actin in isoelectric focusing, and (d) binding to DNase I. The identity of actin and its appearance on the platelet surface after thrombininduced secretion was also demonstrated by the greater binding of an anti-actin antibody to thrombin-treated platelets, measured with ${ }^{125} \mathrm{I}$-staphylococcal protein $\mathrm{A}$.

Therefore, major platelet membrane changes occur after secretion but not after reversible aggregation. The platelet surface changes occurring with secretion

\footnotetext{
A preliminary report of this study was presented to the American Heart Association in November 1978. Circulation. 68: II-217.

Address reprint requests to Dr. George.

Received for publication 21 March 1979 and in revised form 17 January 1980.
}

may be important in the formation of irreversible platelet aggregates and in the final retraction of the blood clot.

\section{INTRODUCTION}

Blood platelets change dramatically from their circulating state during involvement in hemostasis and thrombosis $(1,2)$. They transform from disks to spheres with long pseudopods, aggregate with adjacent platelets, secrete their granule contents into the surrounding environment, accelerate plasma coagulation, and finally bind the developing fibrin strands and provide the power for clot retraction. Since these events must be associated with changes on the platelet membrane, we studied membrane surface proteins during two separable platelet activities: aggregation and secretion. Our studies examined two questions about these reactions. Is surface glycoprotein material lost from platelets during these reactions? Are new proteins exposed on the platelet surface after these reactions?

\section{METHODS}

Blood samples were obtained from normal volunteers, with informed consent, and platelets were isolated as described (3). For one experiment, blood was drawn from a patient with congenital Factor V deficiency (E.N.), who has been studied extensively (4), through the courtesy of Dr. Douglas Triplett, Muncie, Ind.

In the initial part of this study, four basic experiments were performed: $(a)$ stimulation of ${ }^{125}$ I-diazotized diiodosulfanilic acid (DD ${ }^{125}$ ISA) ${ }^{1}$ labeled platelets with ADP, (b) labeling of platelets with DD ${ }^{125}$ ISA after ADP stimulation,

${ }^{1}$ Abbreviations used in this paper: AAA, anti-actin antibody; DD ${ }^{125}$ ISA, ${ }^{125}$ I-diazotized diiodosulfanic acid; GP, glycoprotein; ${ }^{125}$ I-SPA, ${ }^{125}$ I-staphylococcal protein A; PAS, periodic acid-Schiff; PBS, phosphate-buffered saline; $\mathrm{PGE}_{1}$, prostaglandin $\mathrm{E}_{1}$; RCD, Ringer's-citrate-dextrose; SDSPAGE, sodium dodecyl sulfate polyacrylamide gel electrophoresis. 
(c) stimulation of DD ${ }^{125}$ ISA-labeled platelets with thrombin, and $(d)$ labeling of platelets with DD ${ }^{125}$ ISA after thrombin stimulation.

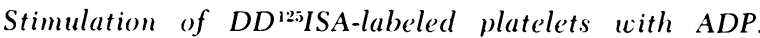
Platelets were isolated from platelet-rich plasma, washed three times in Ringer's citrate-dextrose (RCD)-prostaglandin $\mathrm{E}_{1}\left(\mathrm{PGE}_{1}\right.$; kindly provided by Dr. John E. Pike, Upjohn, Co., Kalamazoo, Mich., final concentration $50 \mathrm{ng} / \mathrm{ml}$ ), and labeled with DD ${ }^{125}$ ISA as described (3). Then the labeled platelets were washed once in Tyrode's buffer (5) containing PGE (50 $\mathrm{ng} / \mathrm{ml}$ ) and apyrase $(25 \mu \mathrm{g} / \mathrm{ml}$, Sigma Chemical Co., St. Louis, Mo.), pH 6.5, and resuspended to $2 \times 10^{9} / \mathrm{ml}$ in Tyrode's-apyrase, pH 7.35, without $\mathrm{PGE}_{1}$. Fibrinogen [Kabi, Stockholm, previously adsorbed with $\mathrm{Al}(\mathrm{OH})_{3}$ ] (6) was added to a final concentration of $0.5 \mathrm{mg} / \mathrm{ml}$ and $\mathrm{CaCl}_{2}$ was added to a final concentration of $2 \mathrm{mM}$. ADP (Sigma Chemical Co.), added to a final concentration of $50 \mu \mathrm{M}$, caused visible coarse aggregation within $30 \mathrm{~s}$. At this time, the 1-ml sample was diluted 10 -fold with RCD-PGE f $_{1}$ and incubated at $37^{\circ} \mathrm{C}$ for $10 \mathrm{~min}$. After incubation platelet aggregates had completely dispersed and only single platelets were present in the suspension. We have previously shown that no serotonin is released by ADP with these conditions (3). Platelets were then washed twice more with RCD-PGE 1 before sodium dodecyl sulfate-polyacrylamide gel electrophoresis (SDS-PAGE) analysis. In parallel control samples either ADP was omitted, or PGE $1(0.5 \mu \mathrm{g} / \mathrm{ml})$ was added before ADP, to prevent aggregation.

Labeling of platelets with DD ${ }^{12.5} I S A$ after ADP stimulation. For these experiments, platelets were washed twice in Tyrode's-apyrase- $\mathrm{PGE}_{1}, \mathrm{pH} 6.5$, and resuspended in Tyrode'sapyrase, $\mathrm{pH} 7.35$, with fibrinogen and $\mathrm{CaCl}_{2}$, as described above. After ADP stimulation and disaggregation, platelets were washed once in RCD-PGE ${ }_{1}$, labeled with DD ${ }^{125} I S A$, then washed twice more in RCD-PGE, before SDS-PAGE analysis.

Stimulation of DD ${ }^{125}$ ISA-labeled platelets with thrombin. Platelets were isolated from platelet-rich plasma, washed three times in RCD-PGE ${ }_{1}$, and labeled with DD ${ }^{125}$ ISA. Then the labeled platelets were washed once in Tyrode's-PGE ${ }_{1}$, $\mathrm{pH} 6.5$, and resuspended to $2 \times 10^{9} / \mathrm{ml}$ in $1 \mathrm{ml}$ of Tyrode'sEDTA $(4 \mathrm{mM})$, pH 7.35 , for thrombin stimulation. Homogeneous human $\alpha$-thrombin $(2,600 \mathrm{U} / \mathrm{mg}$, a gift from Dr. John W. Fenton, New York State Department of Health, Albany, N.Y.) was added to a concentration of $2 \mathrm{U} / \mathrm{ml}$ and the suspension incubated at $37^{\circ} \mathrm{C}$ for $5 \mathrm{~min}$. No platelet aggregation occurred. After thrombin stimulation the platelets were washed once in $\mathrm{RCD}-\mathrm{PGE}_{1}-p$-tosyl-L-arginine methyl ester ( $1 \mathrm{mM}$, Sigma Chemical Co.)-EDTA $(4 \mathrm{mM})$ and then washed twice more with RCD-PGE 1 before SDS-PAGE analysis.

Labeling of platelets with DD ${ }^{125} I S A$ after thrombin stimulation. For these experiments, platelets were washed twice in Tyrode's-PGE, pH 6.5, and resuspended in Tyrode'sEDTA, pH 7.35, as described above. After thrombin stimulation, the platelets were washed once in $\mathrm{RCD}-\mathrm{PGE}_{1}-p$ tosyl-L-arginine methyl ester-EDTA, labeled with DD${ }^{125}$ ISA, then washed twice more in RCD-PGE 1 before SDS-PAGE analysis.

SDS-PAGE analysis. Whole platelets resuspended in RCD-EDTA-N - carbobenzoxy - L - glutamyl - L - tyrosine phenylmethyl sulfonyl fluoride (3) were solubilized in 3\% SDS and $40 \mathrm{mM}$ dithiothretiol (Sigma Chemical Co.) at $100^{\circ} \mathrm{C}$ for $5 \mathrm{~min}$ and $200 \mu \mathrm{g}$ of protein (7) was applied to each gel. Gel electrophoresis (8), staining, and quantitative analysis of the SDS-PAGE data were performed as described (3). Molecular weight standards were rabbit muscle myosin $(200,000), \beta$-galactosidase $(130,000)$, bovine serum albumin
$(68,000)$, and ovalbumin $(43,000)$ (3). Quantitation of the periodic acid-Schiff (PAS) reaction was performed by planimetry of the gel scans. Platelet glycoprotein peaks were converted to "PAS units" by dividing the area of each peak by the area of an internal fetuin (Sigma Chemical Co.) standard (3). The percentage of glycoprotein (GP)-G secretion was calculated by this planimetry method (3). The PASstaining GP bands and the 40,000-mol wt band containing actin, identifiable as a dense white precipitate in the PASstained gel, were marked on the gel with ink, the gel was cut into $1-\mathrm{mm}$ slices, and the radioactivity quantified as described (3). DD ${ }^{125}$ ISA bound to GP-G or the $40,000-\mathrm{mol}$ wt protein was expressed as a fraction of the radioactivity in the four major membrane GP on the same gel. In one experiment, analysis of $\mathrm{DD}^{125}$ ISA-labeled samples was performed using $1.2-\mathrm{mm}$ thick slab gels by modifications (9) of the SDS-PAGE systems described by Weber and Osborn (8), Laemmli (10), and Neville (11). Protein staining and autoradiography were performed as described (9).

Extraction of a platelet particulate faction by $0.3 \mathrm{m.M}$ phosphate buffer. The extraction was performed by the method of Bennett and Branton (12). In these experiments, platelets were labeled by DD ${ }^{125}$ ISA after thrombin stimulation as described above. Then the platelets were disrupted by sonication in RCD-EDTA-N-carbobenzoxy-L-glutamylL-tyrosine-phenylmethyl sulfonyl fluoride (3) and centrifuged at $4^{\circ} \mathrm{C}$ at $150,000 \mathrm{~g}$ for $60 \mathrm{~min}$ (Beckman Instruments Inc., Fullerton, Calif.; L5-50 ultracentrifuge, 50 Ti rotor). The pellet was suspended in $0.3 \mathrm{mM}$ sodium phosphate buffer, $\mathrm{pH} 7.6$, incubated at $37^{\circ} \mathrm{C}$ with shaking for $30 \mathrm{~min}$, and centrifuged again as above to recover the supernatant fluid.

Isoelectric focusing. Isoelectric focusing was performed on the $0.3 \mathrm{~m} . \mathrm{M}$ phosphate extract by the methods of $\mathrm{O}^{\prime} \mathrm{F}$ arrell (13) and Ames (14). To the extract ( $1.5 \mathrm{mg}$ protein/ml) urea (9.5 M, ultra-pure, Schwarz/Mann, Div., Becton, Dickinson \& Co., Orangeburg, N. Y.), nonidet P-40 (2\%, Particle Data, Inc., Elmhurst, Ill.), dithiothreitol $(40 \mathrm{mM}), \operatorname{SDS}(0.2 \%$, Pierce Chemical Co., Rockford, Ill.), and ampholines (4\%; Pharmacia Fine Chemicals, Inc., Piscataway, N. J.) were added to a final concentration. The ampholines were a mixture of equal parts of two $\mathrm{pH}$ ranges, 4.0-6.0 and 6.0-8.0. The sample was then heated to $100^{\circ} \mathrm{C}$ for $5 \mathrm{~min}$. Polyacrylamide gels, sample overlay solution, and electrode solutions were prepared according to O'Farrell (13), except that ampholine concentration was increased to $4 \%$. 7 -cm long gels were formed in 3-mm Diam plastic tubes and isoelectric focusing was performed in a gel electrofocusing chamber (Medical Research Apparatus Corp., Clearwater, Fla.) at $300 \mathrm{~V}$ for $7 \mathrm{~h}$. The $\mathrm{pH}$ gradient for each experiment was determined from two blank gels (identical except for the absence of sample protein) cut into $5-\mathrm{mm}$ sections and eluted in $1 \mathrm{ml}$ of $10 \mathrm{mM}$ $\mathrm{KCl}$ for $20 \mathrm{~min}$. Gels were stained with Coomassie Blue (3) after rinsing for $48 \mathrm{~h}$ in $25 \%$ isopropanol, $10 \%$ acetic acid and then cut into $2.5 \mathrm{~mm}$-sections for determination of radioactivity.

DNase affinity chromatography. DNase affinity chromatography was performed using DNase I (Sigma Chemical Co., DN-CL type I, bovine pancreas) conjugated to Sepharose $6 \mathrm{~B}-\mathrm{CL}(2 \mathrm{mg} / \mathrm{ml}$ of Sepharose beads) (15). $1 \mathrm{ml}$ of the same $0.3 \mathrm{mM}$ phosphate extract described above was applied to a $2 \mathrm{ml}$ DNase-Sepharose column, which was then washed with $25 \mathrm{ml}$ of $0.3 \mathrm{mM}$ phosphate, $\mathrm{pH} 7.6$, before elution with $3.0 \mathrm{M}$ guanidine- $\mathrm{HCl}$ in $0.5 \mathrm{M}$ sodium acetate, $10 \mathrm{mM}$ Tris$\mathrm{HCl}, 0.5 \mathrm{mM} \mathrm{ATP}$, and $0.5 \mathrm{mM} \mathrm{CaCl}_{2}, \mathrm{pH} 7.5$ (15) (referred to as $3 \mathrm{M}$ guanidine buffer).

Platelet lysis. Platelet lysis was quantified by the ${ }^{5} \mathrm{Cr}$ release method of Aster and Enright (16). Platelets were handled exactly as described above for thrombin treatment except that they were labeled with $50 \mu \mathrm{Ci}$ of ${ }^{51} \mathrm{Cr}\left(\mathrm{Na}^{51} \mathrm{CrO}_{4}\right.$, 
Amersham Corp., Arlington Heights, Ill.) at room temperature for $30 \mathrm{~min}$ after the first wash.

Detection of platelet-bound immunoglobulin (Ig)G with ${ }^{125}$ I-staphylococcal protein A ( $\left.{ }^{125} I-S P A\right)$. Anti-actin antibody (AAA) was a gift of Professor Giulio Gabbiani (Geneva, Switzerland). The antibody was isolated from the serum of a patient with chronic active hepatitis by affinity chromatography on Sepharose-rabbit skeletal muscle actin and has been used in several studies (17-19). Rabbit anti-human platelet antiserum was prepared by immunizing rabbits with washed whole platelets emulsified in Freund's adjuvant. Nonimmune human IgG was purified by DEAE-cellulose chromatography.

The use of ${ }^{125}$ I-SPA to quantify IgG bound to fixed cells in microtiter plates was developed by Zeltzer et al. $(20,21)$ and this method has recently been adapted to the study of platelets by Spiva and Zeltzer (22). Staphylococcal protein A (Pharmacia Fine Chemicals, Inc.) was iodinated with ${ }^{125} \mathrm{I}$ by the chloramine $\mathrm{T}$ method $(20,21)$ to $\sim 4 \mu \mathrm{Ci} / \mu \mathrm{g}$ sp act and stored in individual aliquots at $1 \mathrm{mg} / \mathrm{ml}$ in phosphate-buffered saline (PBS) $1 \%$ ovalbumin, $\mathrm{pH} 7.4$, at $-70^{\circ} \mathrm{C}$. Before use the ${ }^{125} \mathrm{I}-\mathrm{SPA}$ was diluted to $2 \mu \mathrm{g} / \mathrm{ml}$ in PBS-ovalbumin. Platelets, thrombin-treated and control, were prepared for these experiments as described above (without $\mathrm{DD}^{125}$ ISA labeling), suspended to a concentration of $10^{8} / \mathrm{ml}$ in RCD-PGE , $_{1}$ and then $50-\mu$ l aliquots were added to microtiter wells and allowed to dry at $46^{\circ} \mathrm{C}$ overnight. The dry platelet pellets were fixed with $10 \%$ methanol and washed with PBS. Then $100 \mu \mathrm{l}(1.58 \mu \mathrm{g})$ of AAA, anti-human platelet antiserum, or nonimmune monomeric human IgG were added to each well and incubated at room temperature for $60 \mathrm{~min}$. The platelet pellets were washed three times in PBS and $100 \mu \mathrm{l}(0.2 \mu \mathrm{g})$ of ${ }^{125} \mathrm{I}-\mathrm{SPA}$ as added to each well and the plate incubated again for $60 \mathrm{~min}$ at room temperature. Then the platelet pellets were washed again in PBS, allowed to dry at $46^{\circ} \mathrm{C}$ overnight, and radioactivity determined.

Statistical comparisons. Statistical comparisons were performed by $t$ test (23).

\section{RESULTS}

In the first part of this study, four basic experiments were performed: $(a)$ stimulation of DD ${ }^{125}$ ISA-labeled platelets with ADP, $(b)$ labeling of platelets with DD ${ }^{125}$ ISA after ADP stimulation, $(c)$ stimulation of $\mathrm{DD}^{125}$ ISA-labeled platelets with thrombin, and $(d)$ labeling of platelets with $\mathrm{DD}^{125} \mathrm{ISA}$ after thrombin stimulation. In each experiment platelets were analyzed by quantitative SDS-PAGE (3). Fig. 1 shows the pattern of the PAS stain of normal whole platelets and the fetuin standard. GP-G is the major GP of platelet granules and is secreted during the platelet release reaction $(3,24)$. It has also been termed "thrombin-sensitive protein" ( 25 and "thrombospondin" (26).

Effect of ADP-induced platelet aggregation on platelet membrane proteins. No significant loss of surface GP occurred during the reversible aggregation unaccompanied by platelet secretion caused by ADP stimulation of $\mathrm{DD}^{125}$ ISA-labeled platelets, as determined by PAS staining and DD ${ }^{125}$ ISA labeling (six experiments, $P>0.1$ ). Also, no change in the pattern of radioisotope labeling was observed when $\mathrm{DD}^{125}$ ISA was reacted with platelets that had previously undergone aggregation and disaggregation (three experi-

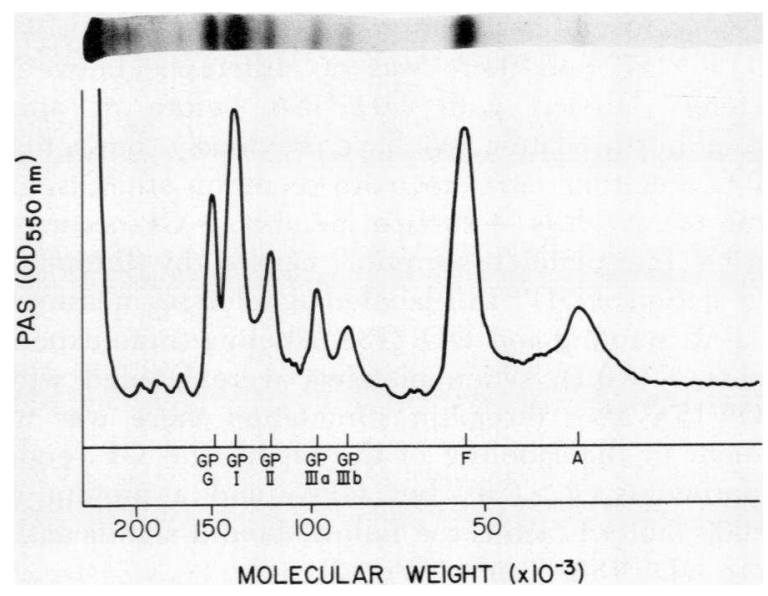

Figure 1 Platelet GP. PAS stain of whole platelet proteins separated by SDS-PAGE. A: photograph of the gel after PAS staining. B: densitometry scan of this gel. $200 \mu \mathrm{g}$ of dithiothreitol-reduced protein plus $5 \mu \mathrm{g}$ of fetuin were applied to the gel, as described in Methods. The band labeled A (for actin) does not stain pink for carbohydrate by the PAS reaction but is seen on the gel as an opaque white band and is detected by densitometry. The platelet GP are described by the nomenclature we have previously presented (3): GP-G (mol wt 149,000), GP-I (mol wt 140,000), GP-II (mol wt 120,000), GP-IIIa (mol wt 98,000), and GP-IIIb (mol wt $88,000)$. The added fetuin is labeled as $F$. The minor high molecular weight PAS bands were not labeled by DD $^{125}$ ISA and not seen regularly enough to be quantitatively analyzed.

ments, $P>0.5)$. Specifically, no new DD ${ }^{125}$ ISAlabeled peaks were present in the gel slices containing GP-G and actin (Table I).

Effect of thrombin-induced platelet secretion on platelet membrane proteins. Platelet secretion of

\section{TABLE I}

Effect of ADP-induced Aggregation and Thrombin-induced Secretion on the Surface Exposure of Actin and GP-G to DD ${ }^{125} I S A$

\begin{tabular}{lcr}
\hline & \multicolumn{1}{c}{ Actin } & \multicolumn{1}{c}{ GP-G } \\
\hline & \multicolumn{2}{c}{$\%$ membrane GP cpm } \\
ADP & $5.7 \pm 0.8$ & $3.3 \pm 2.5$ \\
Control & $5.9 \pm 1.1$ & $3.1 \pm 2.3$ \\
Thrombin & $12.6 \pm 3.7$ & $10.2 \pm 1.0$ \\
Control & $6.3 \pm 1.7$ & $3.9 \pm 0.9$ \\
\hline
\end{tabular}

The data are the mean values $( \pm \mathrm{SD})$ for four experiments in which platelets were labeled with $D^{125}$ ISA after reversible ADP aggregation and eight experiments in which platelets were labeled with DD ${ }^{125}$ ISA after thrombin-induced secretion. Release of GP-G was $61 \pm 16 \%$ (SD) with thrombin but did not occur with ADP. There was no difference in labeling of either actin or GP-G between ADP-treated platelets and their controls $(P>0.5)$. In contrast, the DD ${ }^{125}$ ISA bound to either actin or GP-G after thrombin treatment was significantly greater than control values $(P<0.001)$. 
GP-G occurred in each thrombin experiment $(53 \pm 19 \%$ $\mathrm{SD}, n=17)$ and there was no difference between platelets labeled with DD ${ }^{125}$ ISA before or after thrombin stimulation. We have previously shown that GP-G secretion correlates with secretion of $\left[{ }^{14} \mathrm{C}\right]$ serotonin (3). No loss of surface membrane GP occurred during the platelet secretion caused by thrombin stimulation of $\mathrm{DD}^{125}$ ISA-labeled platelets, as measured by PAS staining and DD ${ }^{125}$ ISA labeling (nine experiments, $P>0.1$ ). When platelets were labeled with DD ${ }^{125}$ ISA after thrombin stimulation there was no change in the labeling of the membrane GP (eight experiments, $P>0.3$ ), but GP-G and a protein at 40,000 mol wt (actin, see below) bound significantly more DD ${ }^{125}$ ISA (Table I, Fig. 2).

We considered the possibility that the change of DD ${ }^{125}$ ISA labeling after thrombin stimulation might be due to lysis of a small fraction of platelets rather than exposure of new proteins on the membrane surface. This possibility was ruled out in two ways. First, the amount of platelet lysis was directly assessed by ${ }^{51} \mathrm{Cr}$ release during each of the steps of thrombin treatment and subsequent $\mathrm{DD}^{125} \mathrm{ISA}$ labeling. ${ }^{51} \mathrm{Cr}$ release was not different in thrombin-treated and control platelets (thrombin-treated, $2.0 \pm 0.3 \%$; control, $1.8 \pm 0.4 \%$; SD, $n=4)$. Second, the $\mathrm{DD}^{125}$ ISA labeling pattern of sonicated platelets was compared to that of thrombin-treated platelets. After lysis by sonication an actin-region protein was the most prominent peak, however none of the other major DD ${ }^{125}$ ISA peaks of lysed platelets coincided with proteins that were labeled after thrombin. We calculated that the DD125ISA peaks seen in the platelet sonicate would have been readily apparent if the actin peak after thrombin stimulation was the result of cell lysis.
Identification of GP-G and actin as the proteins appearing on the platelet surface after thrombininduced secretion. The new $149,000 \mathrm{~mol}$ wt DD${ }^{125}$ ISA-labeled peak observed after thrombin secretion was identified as GP-G because of its exact and consistent correlation with the GP-G PAS band. Because the appearance of GP-G on the platelet surface after secretion, its molecular weight, and its GP nature were all reminiscent of coagulation Factor $\mathrm{V}(4,27$, 28), we speculated that GP-G could be coagulation Factor $\mathrm{V}$ and studied the platelets from a patient who had previously been demonstrated to have no platelet Factor V activity (4). The PAS and Coomassie stain patterns of platelets from this patient were normal in both unreduced and reduced SDS-PAGE analyses both before and after thrombin treatment. After secretion both GP-G and the actin-region protein were labeled by DD ${ }^{125}$ ISA. Therefore, GP-G is likely not platelet Factor V.

Although actin is the major component of the dense 40,000-mol wt protein band of platelets analyzed by SDS-PAGE, this region may also contain several other proteins (9). Therefore, experiments were performed to identify this $\mathrm{DD}^{125}$ ISA peak as actin. Some platelet proteins in this molecular weight region, but not actin, migrate at different apparent molecular weights in different SDS-PAGE systems (9). Fig. 3 demonstrates that the DD ${ }^{125}$ ISA peak comigrated with actin in three different SDS-PAGE systems. Fig. 4A demonstrates that the 40,000-mol wt DD ${ }^{125}$ ISA peak was associated with a particulate fraction and was eluted in a low ionic strength buffer previously demonstrated to preferentially solubilize actin from membranes (12). Fig. 4B demonstrates that the isoelectric point of this DD ${ }^{125}$ ISA peak was identical to that of actin. The isoelectric

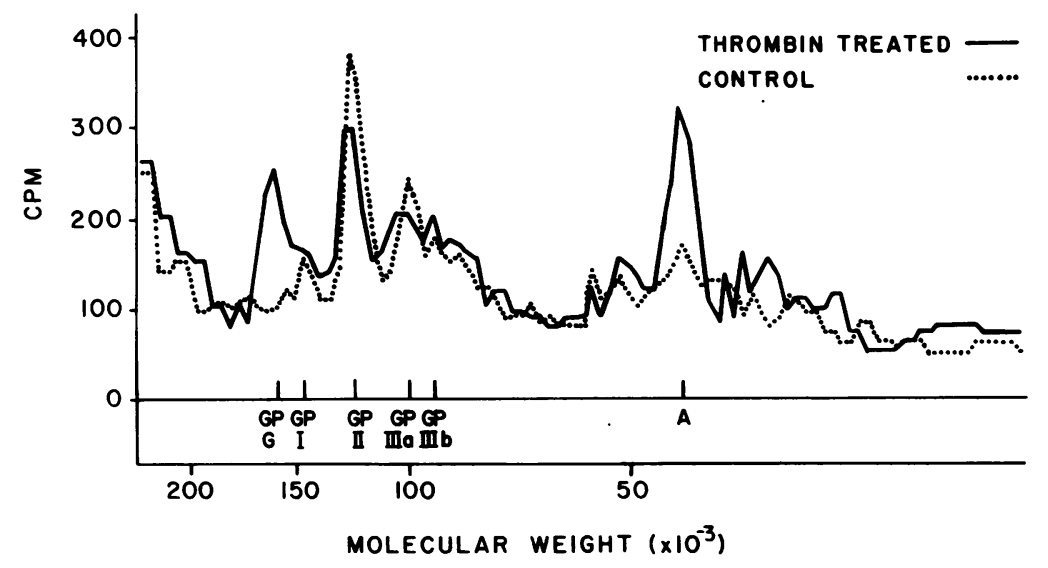

FIGURE 2 Effect of thrombin on the surface exposure of platelet membrane proteins to $D^{125}$ ISA. Platelets were treated with thrombin in the presence of EDTA to stimulate secretion without aggregation, washed, labeled with $\mathrm{DD}^{125} \mathrm{ISA}$, and then analyzed by SDS-PAGE as described in Methods. Thrombin was omitted from the control sample. Gels were stained by PAS, the GP and actin bands were marked by ink, and then the gels were sliced for determination of radioactivity. The gel slices containing ink marks are shown on the abscissa. 


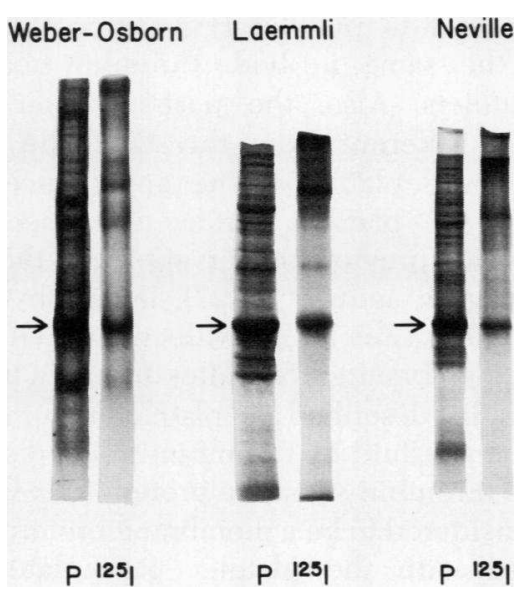

FIGURE 3 DD ${ }^{125}$ ISA labeling of platelet membrane proteins after thrombin-induced secretion: comparison of three SDS-PAGE systems. Platelets were treated with thrombin in the presence of EDTA to stimulate secretion without aggregation, washed, labeled with $\mathrm{DD}^{125} \mathrm{ISA}$, and then solubilized in SDS-dithiothreitol as described in Methods. Aliquots containing $20 \mu \mathrm{g}$ of protein were applied to each of three separate SDS-PAGE slab systems as described by Weber-Osborn (8), Laemmli (10), and Neville (11). After electrophoresis, gels were stained for protein by Coomassie Blue and then autoradiography was performed on the same gels. The gels and their autoradiograms were aligned exactly as previously described (9). Photographs of the protein stain (P) and autoradiogram $\left({ }^{125} \mathrm{I}\right)$ are shown for each sample. The position of actin was identified by coelectrophoresis with homogeneous actin (9) and is marked by the arrows.

point of the radioactive peak, which coincided with the major Coomassie-stained protein band, was 5.78 (see Fig. 4, gel P). This also coincided with one of the two bands present after isoelectric focusing of a preparation of homogeneous platelet actin (Fig. 4, gel A). The other band in the actin sample had an isoelectric point of 5.43. These two bands may represent the previously reported $\gamma$ and $\beta$ forms of platelet actin (29). Actin binds with high affinity to DNase I and can be eluted with $3 \mathrm{M}$ guanidine (15). For DNase I affinity experiments, the same $0.3 \mathrm{mM}$ phosphate extract as shown in Fig. 4A was used. Fig. 5 demonstrates that this DD ${ }^{125}$ ISA-labeled protein bound to DNase I and was eluted by $3 \mathrm{M}$ guanidine. In three experiments, the fraction of counts per minute bound to DNase I was $84 \pm 12 \%$ (SD). A $0.3 \mathrm{mM}$ phosphate extract of DD ${ }^{125}$ ISA-labeled control platelets (thrombin omitted) contained strikingly less counts per minute with the ability to bind to DNase I (Fig. 5).

Identification and quantification of platelet surface actin using an AAA. A specific AAA isolated from human serum (17-19) was reacted with thrombintreated and control platelets and antibody binding was quantified using ${ }^{125}$ I-SPA. ${ }^{125}$ I-SPA binds specifically to the Fc portion of IgG (30) and therefore can be used as a sensitive reagent for the detection of platelet-bound antibody (20-22, 30, 31). Table II demonstrates that thrombin-treated platelets bound significantly more AAA than control platelets. In contrast, binding of nonimmune IgG and a rabbit anti-platelet antibody was the same in both thrombin-treated and control platelets. These experiments confirmed the appearance of actin on the platelet surface after thrombininduced secretion.

\section{DISCUSSION}

The occurrence of platelet membrane changes during activation has been demonstrated by changes in a variety of platelet functions, such as increased adhesiveness to subendothelium (32) and acceleration of coagulation (4). To characterize the membrane surface protein changes that accompany platelet activation, we used washed human platelets in conditions that allowed independent assessment of two major platelet reactions: aggregation and secretion.

Effect of aggregation on platelet membrane proteins. Our studies demonstrated no loss of platelet surface GP during reversible ADP-induced platelet aggregation without secretion. Also we demonstrated no change in the DD ${ }^{125}$ ISA labeling of membrane GP and no exposure of new proteins on the membrane surface after reversible aggregation, similar to the results of Jenkins et al. (33) using lactoperoxidase-catalyzed iodination. These results with human platelets in vitro are analogous to our in vivo studies of circulating rabbit platelets double-labeled with DD${ }^{125} \mathrm{ISA}$ for surface GP (34) and ${ }^{51} \mathrm{Cr}$ for internal cytoplasm. When these rabbits were given intravenous ADP, two-thirds of their platelets were removed from the circulation in less than $1 \mathrm{~min}$ but all returned to the circulation by $3 \mathrm{~min}$. There was no loss of platelet surface GP during this reversible ADP-induced sequestration (35). Therefore platelets may be able to resume their normal function in the circulation after transient aggregation. The recovery of the platelet membrane to a normally reactive state after reversible aggregation is also suggested by the response of experimental animals to repeated ADP infusions, with no apparent loss of platelet sensitivity to aggregation (36).

Effect of secretion on platelet membrane proteins. Our studies demonstrated no loss of platelet surface GP during thrombin-induced secretion (without aggregation). These results are similar to those of Hagen et al. (37) who studied platelets labeled with [ ${ }^{125}$ I] lactoperoxidase. Our results differ from those of Phillips and Agin $(38,39)$ and Mosher et al. $(40)$, but different experimental systems were used in those studies.

Although there was no change in $\mathrm{DD}^{125}$ ISA labeling of the membrane GP after thrombin-induced secretion, two new proteins were labeled: actin and the major granule GP, GP-G. The labeling pattern after secretion 

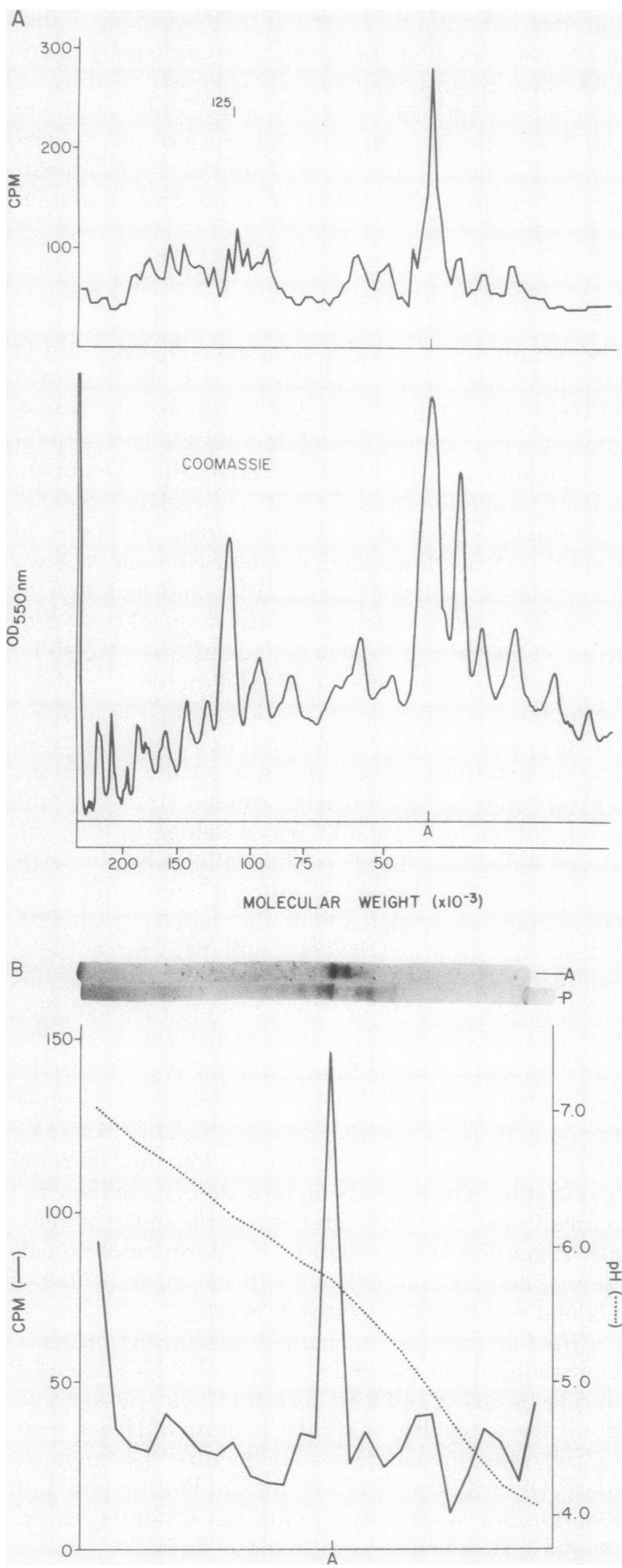

FIGURE 4 DD ${ }^{125}$ ISA labeling of platelet membrane proteins after thrombin-induced secretion: analysis by extraction in low ionic strength buffer and isoelectric focusing. was not related to platelet lysis since the percent lysis was the same in both thrombin-treated and control platelets. Also, the post-secretion labeling pattern was different from the $\mathrm{DD}^{125}$ ISA labeling pattern of lysed platelets. The appearance of new proteins on the platelet surface after secretion is consistent with previous observations of the appearance of Factor $\mathrm{V}$ activity $(2,27)$, lentil phytohemagglutinin binding sites (41), and lectin activity (42) on the platelet membrane surface after thrombin treatment.

GP-G was first described as a platelet protein released into supernatant fluid by thrombin-induced secretion, and termed thrombin-sensitive protein (25). GP-G was initially considered to be a membrane protein because it remained with the platelet particulate fraction after a sonication procedure that completely solubilized a lyzosomal enzyme, $\beta$-glucuronidase (25). Subsequently, GP-G has been demonstrated to be a secreted granule protein $(24,26)$. The appearance of GP-G on the platelet surface may be due to adsorption of secreted GP-G onto the membrane, or related to the process of granule fusion with the plasma membrane during secretion (43), if some GP-G remains adherent to the internal surface of the granule membrane.

Identification of actin on the platelet surface after thrombin-induced secretion. The appearance of actin on the platelet surface after thrombin-induced secretion was demonstrated by two independent methods: (a) labeling with DD ${ }^{125}$ ISA and $(b)$ binding of AAA. Four sets of experiments suggested the 40,000-mol wt protein labeled by $\mathrm{DD}^{125}$ ISA after secretion was actin: (a) The labeled protein comigrated with actin in three different SDS-PAGE systems $(8,10,11)$. (b) The labeled protein was extracted from a platelet particulate fraction by $0.3 \mathrm{mM}$ phosphate (12) and was thereby separated from intrinsic membrane proteins. (c) This extracted, labeled protein comigrated with actin during isoelectric focusing and had an isoelectric point of 5.78 , similar to the isoelectric point reported for

(A) Platelets were treated with thrombin in the presence of EDTA to stimulate secretion without aggregation, washed, labeled with DD ${ }^{125}$ ISA, sonicated, and centrifuged at $150,000 \mathrm{~g}$ for $60 \mathrm{~min}$. This pellet was extracted with $0.3 \mathrm{mM}$ phosphate, pH 7.6, as described in Methods, and analyzed by SDS-PAGE. The gel was stained with Coomassie Blue and the dense protein band marked (A on abscissa). Then the gel was sliced for determination of radioactivity and the peak counts per minute occurred in the marked slice (top). (B) This $0.3 \mathrm{mM}$ phosphate extract was then analyzed by isoelectric focusing as described in Methods. A photograph of the Coomassie-stained gel is shown at the top (labeled P) with a gel from simultaneous analysis of homogeneous platelet actin (labeled A) purified as described (9). The most dense protein band on the platelet sample was marked, and then the gel was sliced for determination of radioactivity. The peak of radioactivity occurred in the marked gel slice ( $A$ on the abscissa of the counts per minute graph). The $\mathrm{pH}$ gradient was determined from slices of two simultaneous blank gels. 


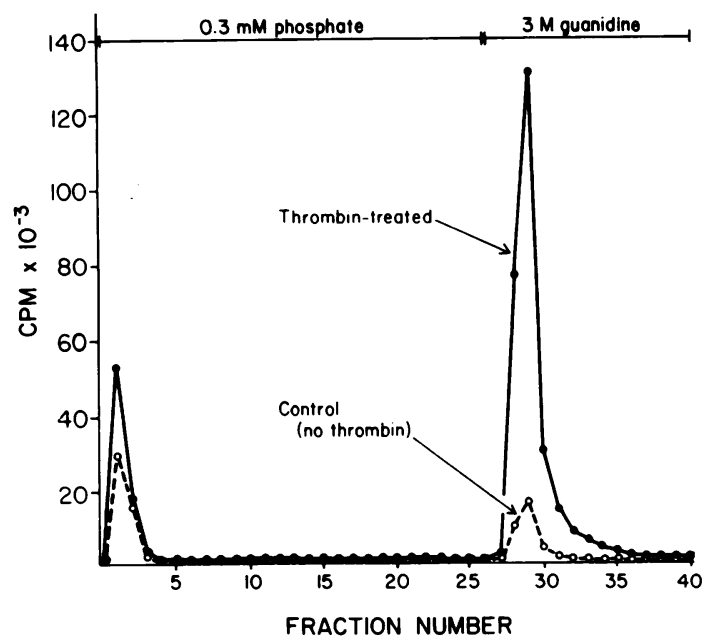

FIGURE 5 DD ${ }^{125}$ ISA labeling of platelet membrane proteins after thrombin-induced secretion: analysis by DNase I affinity chromatography. The platelet particulate fraction was extracted with $0.3 \mathrm{m.M}$ phosphate, $\mathrm{pH} 7.6$ as described in Methods and Fig. $4.1 \mathrm{ml}$ of this extract was applied to the DNase-Sepharose column which was then

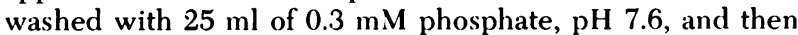
actin was eluted with $3 \mathrm{M}$ guanidine. In a control experiment, a $0.3 \mathrm{mM}$ phosphate extract was prepared from DD ${ }^{125}$ ISAlabeled platelets that had not been treated with thrombin and this extract was similarly analyzed by DNase I affinity chromatography.

platelet actin (29) and to our results with homogeneous platelet actin. (d) This extracted, labeled protein bound to DNase I and was eluted by $3 \mathrm{M}$ guanidine (15). Our experiments with a specific AAA (17-19) also demonstrated the appearance of actin on the platelet surface after thrombin-induced secretion, and therefore strongly supported the data that the 40,000 mol wt protein labeled by $\mathrm{DD}^{125} \mathrm{ISA}$ is actin.

\section{TABLE II}

Effect of Thrombin-induced Secretion on the Platelet Binding of AAA and Anti-Platelet Antibody

\begin{tabular}{lcc}
\hline & AAA & Anti-platelet antibody \\
\hline & \multicolumn{2}{c}{$c p m$ of platelet-bound ${ }^{125} I-\mathrm{SPA}$} \\
Thrombin-treated & & \\
$\quad$ platelets & $8,713 \pm 670$ & $15,757 \pm 1,660$ \\
Control platelets & $3,592 \pm 998$ & $18,039 \pm 390$ \\
$P$ & $<0.005$ & $>0.2$ \\
\hline
\end{tabular}

The data are the mean values $( \pm S E M)$ for five experiments. Platelet-bound antibody was determined by the subsequent binding of ${ }^{125}$ I-SPA. As a control, the ${ }^{125}$ I-SPA counts per minute bound to platelets reacted with nonimmune IgG were subtracted from each sample. Nonimmune IgG bound equally to thrombin-treated and control platelets, $P>0.7$, averaging 7,678 counts per minute of ${ }^{125}$ I-SPA for all samples.
Actin is a membrane-associated protein in many cells with postulated functions in the regulation of cell shape and cell motility $(44,45)$. The intimate association of actin filaments and surface membranes has been shown by freeze-fracture studies of choroid plexus and intestinal microvilli: the microfilaments were predominantly attached to the exposed surface of the external half-membrane and therefore penetrated the internal half-membrane (46). Although actin is not normally considered to be a cell surface protein, it has been detected on the external surface of lymphocytes by lactoperoxidase-catalyzed iodination (47) and two studies with immunofluorescent techniques have suggested the appearance of actin on the surface of human platelets during activation $(48,49)$.

Alpha actinin functions as the membrane attachment site for actin microfilaments in the tips of intestinal microvilli $(50,51)$. Evidence has been presented that platelet membrane GP IIIa may be $\alpha$ actinin (52). Since this GP may span the plasma membrane (38), it could function to anchor actin to the membrane and mediate the exposure of actin on the platelet surface. Therefore we studied platelets from four patients with Glanzmann's thrombasthenia, which are deficient in GP IIIa and therefore, deficient in alpha actinin (52-54). Our preliminary data (55, plus observations on two more patients) demonstrated that these platelets released GP-G normally in response to thrombin and after thrombin treatment GP-G was normally labeled by $\mathrm{DD}^{125}$ ISA. However, there was significantly less increase in actin labeling by $\mathrm{DD}^{125}$ ISA after thrombin treatment in the thrombasthenic platelets than in normals. This is consistent with a hypothesis that membrane GP IIIa ( $\alpha$-actinin) may bind actin within the plasma membrane and that during thrombin-induced platelet activation GP IIIa may undergo a conformational change to expose actin to the external environment. Once exposed on the platelet surface, actin could provide a receptor site for polymerizing fibrin $(56,57)$ and the contractile power for clot retraction. The diminished or absent clot retraction in Glanzmann's thrombasthenia (58) may be related to the diminished actin exposure on the surface of thrombasthenic platelets after thrombin treatment.

\section{ACKNOWLEDGMENTS}

The authors thank Doctors David Sears (San Antonio), David Phillips (Memphis), Rosemarie Käser-Glanzmann (Bern), Alan Nurden (Paris), and Inger Hagen (Oslo) for their help during these experiments and critical review of this manuscript.

This work was supported by National Institutes of Health grants HL 19996, AM 17137, Institutional subgrant 7-06; Morrison Trust Grant R-A-68; a Grant-in-Aid from the American Heart Association with funds contributed in part by 
the Texas affiliate; and the Research Service, Audie L. Murphy Veterans Administration Hospital, San Antonio, Texas.

\section{REFERENCES}

1. White, J. G., and J. M. Gerrard. 1978. Platelet ultrastructure in relation to platelet function. In The Blood Platelet in Transfusion Therapy. T. Greenwalt and G. A. Jamieson, editors. Alan R. Liss, Inc., New York. 5-23.

2. Moroff, G., and G. A. Jamieson. 1978. Biochemical aspects of platelet function. In The Blood Platelet in Transfusion Therapy. T. Greenwalt and G. A. Jamieson, editors. Alan R. Liss, Inc., New York. 25-37.

3. George, J. N. 1978. Studies on platelet plasma membranes. IV. Quantitative analysis of platelet membrane glycoproteins by ( $\left.{ }^{125} \mathrm{I}\right)$-diazotized diiodosulfanilic acid labeling and SDS-polyacrylamide gel electrophoresis. $J$. Lab. Clin. Med. 92: 430-446.

4. Miletich, J. P., D. W. Majerus, and P. W. Majerus. 1978. Patients with congenital Factor V deficiency have decreased factor $\mathrm{X}_{\mathrm{a}}$ binding sites on their platelets.J. Clin. Invest. 62: 824-835.

5. Mustard, J. F., D. W. Perry, N. G. Ardlie, and M. A. Packham. 1972. Preparation of suspensions of washed platelets from humans. Br. J. Haematol. 22: 193-204.

6. Mustard, J. F., D. W. Perry, R. L. Kinlough-Rathbone, and M. A. Packham. 1975. Factors responsible for ADPinduced release reaction of human platelets. Am. J. Physiol. 228: 1757-1765.

7. Lowry, D. H., N. J. Rosebrough, A. L. Farr, and R. J. Randall. 1951. Protein measurement with the Folin phenol reagent. J. Biol. Chem. 193: 265-275.

8. Weber, K., and M. Osborn. 1969. The reliability of molecular weight determination by dodecyl sulfatepolyacrylamide gel electrophoresis. J. Biol. Chem. 244: 4406-4412.

9. Lyons, R. M., and R. M. Atherton. 1979. Characterization of a platelet protein phosphorylated during the thrombininduced release reaction. Biochemistry. 18: 544-552.

10. Laemmli, U. K. 1970. Cleavage of structural proteins during the assembly of the head of bacteriophage T4. Nature (Lond.). 227: 680-685.

11. Neville, D. M., Jr. 1971. Molecular weight determination of protein-dodecyl sulfate complexes by gel electrophoresis in a discontinuous buffer system. J. Biol. Chem. 246: 6328-6334.

12. Bennett, V., and D. Branton. 1977. Selective association of spectrin with the cytoplasmic surface of human erythrocyte plasma membranes. J. Biol. Chem. 252: 2753-2763.

13. O'Farrell, P. H. 1975. High resolution two-dimensional electrophoresis of proteins. J. Biol. Chem. 250: 4407-4021.

14. Ames, G. F-L., and K. Nikaido. 1976. Two dimensional gel electrophoresis of membrane proteins. Biochemistry. 15: $616-623$.

15. Lazarides, E., and U. Lindberg. 1974. Actin is the naturally occurring inhibitor of deoxyribonuclease I. Proc. Natl. Acad. Sci. U. S. A. 71: 4742-4746.

16. Aster, R. H., and S. E. Enright. 1969. A platelet and granulocyte membrane defect in paroxysmal nocturnal hemoglobinuria: usefulness for the detection of platelet antibodies. J. Clin. Invest. 48: 1199-1210.

17. Gabbiani, G., C. Chaponnier, A. Zumbe, and P. Vassalli. 1977. Actin and tubulin co-cap with surface immunoglobulins in mouse B lymphocytes. Nature (Lond.). 296: $697-698$.

18. Gabbiani, G., C. Chaponnier, and I. Hüttner. 1978. Cytoplasmic filaments and gap junctions in epithelial cells and myofibroblasts during wound healing. J. Cell. Biol. 76: 561-568.

19. Prentki, M., C. Chaponnier, B. Jeanrenaud, and G. Gabbiani. 1979. Actin microfilaments, cell shape, and secretory processes in isolated rat hepatocytes. Effect of phalloidin and cytochalasin D. J. Cell. Biol. 81: 592-607.

20. Zeltzer, P. M., and R. C. Seeger. 1977. Microassay using radioiodinated protein A from Staphylococcus aureus for antibodies bound to cell surface antigens of adherent tumor cells. J. Immunol. Methods. 17: 163-175.

21. Zeltzer, P. M., J. S. Pepose, N. H. Bishop, and J. N. Miller. 1978. Microassay for immunoglobulin $G$ antibodies to Treponema pallidum with radioiodinated protein A from Staphylococcus aureus: immunoglobulin G response in experimental syphilis in rabbits. Infect. Immun. 21: 163-170.

22. Spiva, D. A., and P. M. Zeltzer. 1979. The ${ }^{125} \mathrm{I}-$ staphylococcal protein A test for bound and free IgG antiplatelet antibody. Blood. 54(Suppl. 1): 262a. (Abstr.)

23. Snedecor, G. W., and W. G. Cochran. 1967. Statistical Methods. Iowa State University Press, Ames, Iowa. Sixth edition. 59-60.

24. Hagen, I., T. Olsen, and N. O. Solum. 1976. Studies on subcellular fractions of human platelets by the lactoperoxidase-iodination technique. Biochim. Biophys. Acta. 455: 214- 225 .

25. Baenziger, N. L., G. N. Brodie, and P. W. Majerus. 1972. Isolation and properties of a thrombin-sensitive protein of human platelets. J. Biol. Chem. 247: 2723-2731.

26. Lawler, J. W., H. S. Slayter, and J. E. Coligan. 1978. Isolation and characterization of a high molecular weight glycoprotein from human blood platelets. J. Biol. Chem. 253: 8609-8616.

27. Osterud, B., S. I. Rapaport, and K. K. Lavine. 1977. Factor $\mathrm{V}$ activity of platelets, evidence for an activated factor $\mathrm{V}$ molecule and for a platelet activator. Blood. 49: 819-834.

28. Colman, R. W. 1976. Factor V. Prog. Hemostasis Thromb. 3: $109-143$.

29. Landon, R., C. Huc, F. Thomé, C. Oriol, and A. Olomucki. 1977. Human platelet actin. Evidence of $\beta$ and $\gamma$ forms and similarity of properties with sarcomeric actin. Eur. J. Biochem. 81: 517-577.

30. Hawiger, J., S. Steckley, D. Hammond, C. Cheng, S. Timmons, A. D. Glick, and R. M. Des Prez. 1979. Staphylococci-induced human platelet injury mediated by protein $A$ and immunoglobulin $G$ Fc fragment receptor. J. Clin. Invest. 64: 931-937.

31. Hymes, K., S. Shulman, and S. Karpatkin. 1979. A solid phase radioimmunoassay for bound anti-platelet antibody. J. Lab. Clin. Med. 94: 639-648.

32. Baumgartner, H. R., and R. Muggli. 1976. Adhesion and aggregation: morphological demonstration and quantitation in vivo and in vitro. In Platelets in Biology and Medicine. J. L. Gordon, editor. North-Holland Publishing Co., Amsterdam. 23-60.

33. Jenkins, C. S. P., D. R. Phillips, K. J. Clemetson, D. Meyer, M-J. Larrieu, and E. F. Lüscher. 1976. Platelet membrane glycoproteins implicated in ristocetin-induced aggregation. J. Clin. Invest. 57: 112-124.

34. George, J. N., P. C. Lewis, and D. A. Sears. 1976. Studies on platelet plasma membranes. II. Characterization of surface proteins of rabbit platelets in vitro and during circulation in vivo using diazotized $\left({ }^{125} \mathrm{I}\right)$-diiodosulfanilic acid as a label. J. Lab. Clin. Med. 88: 247-260.

35. George, J. N. 1978. Platelet behavior and aging in the circulation. In The Blood Platelet in Transfusion Therapy. T. Greenwalt and G. A. Jamieson, editors. Alan R. Liss, Inc., New York. 39-64. 
36. Holmes, I. B., G. M. Smith, and F. Freuler. 1977. The effect of intravenous adenosine diphosphate on the number of circulating platelets in experimental animals: inhibition by prostaglandin $\mathrm{E}_{1}$, dipyridamole, $\mathrm{SH}-869$ and VK-774. Thromb. Haemostasis. 37: 36-46.

37. Hagen, I., N. O. Solum, and T. Olsen. 1977. Membrane alterations in connection with the release reaction in human platelets as studied by the lactoperoxidaseiodination technique and by agglutination with bovine factor VIII-related protein. Biochim. Biophys. Acta. 468: $1-10$.

38. Phillips, D. R., and P. P. Agin. 1974. Thrombin substrates and the proteolytic site of thrombin action on human platelet plasma membranes. Biochim. Biophys. Acta. 352: 218-227.

39. Phillips, D. R., and P. P. Agin. 1977. Platelet plasma membrane glycoproteins: identification of a proteolytic substrate for thrombin. Biochem. Biophys. Res. Commun. 75: 940-947.

40. Mosher, D. F., A. Vaheri, J. J. Choate, and C. G. Gahmberg. 1979. Action of the thrombin on surface glycoproteins of human platelets. Blood. 53: 437-445.

41. Feagler, J. R., T. W. Tillack, D. D. Chaplin, and P. W. Majerus. 1974. The effects of thrombin on phytohemagglutinin receptor sites in human platelets. J. Cell Biol. 60: 541-553.

42. Gartner, T. K., D. C. Williams, F. C. Minion, and D. R. Phillips. 1978. Thrombin-induced platelet aggregation is mediated by a platelet plasma membrane-bound lectin. Science (Wash. D. C.). 200: 1281-1283.

43. Palade, G. 1975. Intracellular aspects of the process of protein synthesis. Science (Wash. D. C.). 189: 347-358.

44. Clark, M., and J. A. Spudich. 1977. Nonmuscle contractile proteins: The role of actin and myosin in cell motility and shape determination. Ann. Rev. Biochem. 46: 797-822.

45. Cohen, I., and E. F. Lüscher. 1975. The blood platelet contractile system. Haemostasis. 4: 127-242.

46. McNutt, N. S. 1978. A thin-section and freeze-fracture study of microfilament-membrane attachments in choroid plexus and intestinal microvilli. J. Cell Biol. 79: 774-787.

47. Owen, M. J., J. Auger, B. H. Barber, A. J. Edwards, F. S. Walsh, and M. J. Crumpton. 1978. Actin may be present on the lymphocyte surface. Proc. Natl. Acad. Sci. U. S. A. 75: 4484-4488.

48. Bouvier, C. A., G. Gabbiani, G. B. Ryan, M-C. Badonnel, G. Majno, and E. F. Lüscher. 1977. Binding of anti-actin autoantibodies to platelets. Thromb. Haemostasis. 37: 321-328.

49. Diggle, T. A., B. H. Toh, B. G. Firkin, and S. L. Pfueller. 1979. Human platelet actin: surface expression after platelet activation. Thromb. Haemostasis. 42: 799-802.

50. Mooseker, M., and L. G. Tilney. 1975. Organization of an actin filament-membrane complex. J. Cell Biol. 67: 725-743.

51. Craig, S. W., and J. V. Pardo. 1979. Alpha-actinin localization in the junctional complex of intestinal epithelial cells. J. Cell Biol. 80: 203-210.

52. Gerrard, J. M., J. F. Schollmeyer, D. R. Phillips, and J. G. White. 1979. $\alpha$-actinin deficiency in thrombasthenia: possible identity of $\alpha$-actinin as glycoprotein III. Am. J. Pathol. 94: 509-528.

53. Phillips, D. R., and P. P. Agin. 1977. Platelet membrane defects in Glanzmann's thrombasthenia. Evidence for decreased amounts of two major glycoproteins. J. Clin. Invest. 60: 535-545.

54. Nurden, A. T., and J. P. Caen. 1979. Different glycoprotein abnormalities in thrombasthenic and Bernard-Soulier platelets. Semin. Hematol. 16: 234-250.

55. George, J. N., and R. K. Morgan. 1979. Actin exposure on the surface of normal platelets and thrombasthenic platelets following thrombin-induced secretion: mediation by platelet membrane $\alpha$-actinin. Thromb. Haemostasis. 42: 68. (Abstr.)

56. Laki, K., and L. Muszbek. 1974. On the interaction of F-actin and fibrin. Biochim. Biophys. Acta. 371: 519525.

57. Nachman, R., R. Levine, and E. Jaffe. 1978. Synthesis of actin by cultured guinea pig megakaryocytes: complex formation with fibrin. Biochim. Biophys. Acta. 543: 91-105.

58. Caen, J. P., P. A. Castaldi, J. C. LeClerc, S. Inceman, M. J. Larrieu, M. Probst, and J. Bernard. 1966. Congenital bleeding disorders with long bleeding time and normal platelet count. I. Glanzmann's thrombasthenia. Am. J. Med. 41: 4-26. 